\title{
PALESTRA INTERATIVA COMO RECURSO PEDAGÓGICO NO CURSO DE LICENCIATURA EM FÍSICA
}

\section{THE USE OF INTERACTIVE LECTURE AS A PEDAGOGICAL RESOURCE IN THE COURSE OF PHYSICS DEGREE}

\author{
Bruna Brilhante da Lágua ${ }^{1}$; Neusa Teresinha Rocha dos Santos²; Márcia de Fátima \\ Barbosa Corrêa ${ }^{3}$
}

\section{INTRODUÇÃO}

O desinteresse dos alunos pelo ingresso nos cursos de licenciatura, principalmente na área de exatas, mostra como nosso modo de ensino pode estar dificultando essa vocação e como a nossa sociedade não acrescenta estímulos aos alunos a serem professores, tornando essa profissão as vezes esquecida na hora de procurar uma carreira.

Dentro do ensino vertical e disciplinar proposto na maioria das escolas brasileiras o aluno não é estimulado a questionar e verificar como os fenômenos do cotidiano e da natureza se comportam, como por exemplo, qual o fenômeno é executado ao abrir uma porta? Onde o aluno identifica a física nesse simples movimento?

Segundo Ausubel "de todos os fatores que influem na aprendizagem, o mais importante é o que o aluno já sabe; Averigue-se isso e ensine-se de acordo.” O autor nos chama atenção sobre a aprendizagem significativa e como a interação de um novo conhecimento se mostra importante e mais interessante ao cérebro que uma aprendizagem mecânica, apenas de repetição.

Partindo dessa premissa e desejando desmistificar a física e estimular o interesse para a docência, especificamente para a área de Física, foi submetido o Projeto Ensino $e$ aprendizagem de física numa perspectiva inclusiva: do incentivo ao estudo a formação inicial de educadores para área de física ao Edital no 144/2017/REIT CGAB/IFRO, de 20 de junho de 2017 para seleção de projetos para o Programa Despertando Vocações para as Licenciaturas - PDVL do Instituto federal de Educação, Ciência e Tecnologia de Rondônia-IFRO. O projeto foi dividido em duas etapas para sua execução: a primeira etapa

\footnotetext{
1 Licenciatura em Física, Instituto Federal de Educação, Ciência e Tecnologia de Rondônia - IFRO, brunaabrilhaante@gmail.com

${ }^{2}$ Colaboradora do PDVL/IFRO, Professora de Língua Portuguesa do curso de Licenciatura em Física, Instituto Federal de Educação, Ciência e Tecnologia de Rondônia - IFRO, neusa.santos@ifro.edu.br

${ }^{3}$ Coordenadora do PDVL/IFRO. Professora de Pedagogia curso de Licenciatura em Física, Instituto Federal de Educação, Ciência e Tecnologia de Rondônia - IFRO, marcia.barbosa@ifro.edu.br
} 
ocorreu no segundo semestre de 2017 e a segunda no primeiro semestre de 2018. Para este relato elegemos a primeira etapa de execução do projeto 2017.2 na qual foram realizadas palestras interativas, trabalhando conteúdos do Ensino Médio (EM).

\section{RELATO DE EXPERIÊNCIA}

A atividade proposta foram palestras interativas, sendo estas realizadas em cinco escolas parceiras, da rede pública estadual de Rondônia, participando novecentos alunos dos $1^{\circ}, 2^{\circ}$ e $3^{\circ}$ anos do Ensino médio, dos turnos vespertino e noturno, no segundo semestre de 2017.

As palestras foram realizadas em três momentos: i) apresentação do curso de Licenciatura em Física do Instituto Federal de Educação, Ciência e Tecnologia de Rondônia (IFRO); ii) apresentação dos experimentos (nomes) de forma geral; iii) apresentação da palestra intitulada: Desmistificando o ensino de física de forma interativa. Neste momento foram demonstrados experimentos como: o uso de nitrogênio - para trabalhar a questão de variação de temperatura; a bicicleta elétrica - para explicação de eletricidade; o canhão de ar para explicar deslocamento de massa de ar; a haste de força - para explicar o torque e o líquido alienígena - para a demonstração de fluídos não newtonianos.

A cada parte da palestra alguns alunos eram convidados a participação dos experimentos, a partir disso eram tecidos comentários sobre como aquele processo físico acontecia, sempre relacionando aos conhecimentos trabalhados na parte teórica da palestra e também em sala de aula.

Podemos citar como exemplo de um momento da palestra interativa a explicação da bicicleta elétrica onde podíamos ver como a energia cinética se transformava em energia elétrica e como as cargas de elétrons eram passadas por meio de corrente. Esse experimento trabalhou o conteúdo de Eletricidade, estudado no $2^{\circ}$ ano do Ensino Médio.

Finalizando a palestra interativa com a demonstração dos experimentos mencionados, os alunos tiveram a oportunidade manusear os experimentos, utilizar, verificando como ocorriam os fenômenos que ali estavam sendo demonstrados com ajuda dos acadêmicos de física. 


\section{CONSIDERAÇÕES}

Consideramos que as palestras interativas foram importantes para incentivar os alunos do Ensino Médio participantes da atividade a estudar física. Demostrando também, que estudar física não é apenas fazer cálculo e que a mesma está em tudo que vivenciamos diariamente. Para os acadêmicos do curso de licenciatura em física envolvidos, o projeto proporcionou uma vivência pedagógica, inserção no ambiente escolar, conhecimento técnicocientífico na área de física, visto que tal recurso, a palestra interativa, pode ser utilizado em sala de aula como estratégia pedagógica.

\section{REFERÊNCIAS}

AUSUBEL, D.P. The psychology of meaningful verbal learning. New York: Grune and Stratton. 685p. (1963). 